\title{
OS NÍVEIS HIERÁRQUICOS DAS CIDADES MÉDIAS DE MINAS GERAIS
}

\author{
Hierarchical levels of \\ medium-size cities in Minas Gerais
}

\author{
Oswaldo Bueno Amorim FILHO1 \\ José Irineu Rangel RIGOTTI 2 \\ Jarvis CAMPOS $^{3}$
}

\begin{abstract}
RESUMO
Desde o final dos anos 1970, três classificações das cidades médias de Minas Gerais foram realizadas por Amorim Filho e associados. A primeira dessas classificações resultou de pesquisas e do tratamento de informações geográficas realizados principalmente no Instituto de Geociências da UFMG entre 1974 e 1981, e publicada em 1982. Desta pesquisa pioneira, participaram também Maria Elizabeth Taitson Bueno (Cartografia) e João Francisco de Abreu (quantificação). Entre 1997 e 1999, já na PUC Minas, Amorim Filho e Abreu voltaram a colaborar e foi realizada a segunda classificação das cidades médias de Minas Gerais, desta vez em conexão com o potencial tecnopolitano desse grupo de cidades. Finalmente, em meados de 2006, Amorim Filho, Rigotti e Campos elaboraram a última dessas classificações, igualmente na PUC Minas. Este trabalho busca apresentar uma reflexão sobre as bases teóricas e metodológicas empregadas nessas três classificações e sobre seus principais resultados.
\end{abstract}

Palavras-chave:

cidades médias; Minas Gerais; classificações hierárquicas.

\begin{abstract}
Since the end of the 1970's three classifications of mediumsized cities in Minas Gerais were developed by Amorim Filho and associates. The first of these classifications is the result from research and the treatment of geographic information carried out mainly at Instituto de Geociências da UFMG, between 1974 and 1981, and published in 1982. Maria Elizabeth Taitson Bueno (Cartography) and João Francisco de Abreu (quantification) also took part in this pioneer research. Between 1997 and 1999, Amorim Filho and Abreu produced at PUC Minas the second classification of medium-sized cities in Minas Gerais, this time in connection with the technopolitan potential of this group of cities. Finally, in 2006, Amorim Filho, Rigotti and Campos developed the last of these classifications, at PUC Minas again. The present work aims at bringing forth a reflection on the theoretical and methodological basis used in these three classifications and on their main results.
\end{abstract}

\section{Key words:}

medium-size cities; Minas Gerais; hierarchies.

\footnotetext{
1 Doutor em Geografia - PUC Minas

2 Doutor em Demografia - PUC Minas

3 Mestrando em Geografia - PUC Minas - infoespa@pucminas.br
} 


\section{A CLASSIFICAÇÃO PIONEIRA DE 1982}

A primeira classificação das cidades médias mineiras só foi possível como um dos resultados de cerca de dez anos de pesquisas sobre esse tema, realizadas a partir de 1969, por Amorim Filho e associados, inicialmente na Fundação Universitária do Oeste de Minas - FUOM - em Formiga; em seguida (1971-1973), na Universidade de Bordeaux III (França); e, entre 1974 e 1981, no Instituto de Geociências da Universidade Federal de Minas Gerais.

Do ponto de vista operacional, a classificação hierárquica e a análise da distribuição dos diferentes níveis deste grupo de cidades nas regiões de Minas Gerais só se tornaram possíveis pela feliz convergência de três contribuições fundamentais: primeiramente, a experiência acumulada por Amorim Filho em uma continuada reflexão teórica sobre o tema das cidades médias e um conhecimento empírico (em dezenas de trabalho de campo) de todas as cidades mineiras susceptíveis de se classificarem como médias; em segundo lugar, a competência desenvolvida por Abreu, no domínio de técnicas quantitativas de classificação (primeiramente hierarquias e tipologias), durante seu doutoramento nos Estados Unidos; finalmente, as habilidades cartográficas e gráficas, especialmente na confecção de mapas temáticos, desenvolvidas por Taitson Bueno, também durante seus estudos na Universidade de Bordeaux III.

O primeiro desafio teórico-metodológico apareceu desde o início, com a necessidade de se definir qual seria o grupo de cidades a ser estudado e classificado, uma vez que não fazia sentido, para a finalidade que os autores se propunham, levantar informações sobre todas as 722 cidades de então, em Minas Gerais. Assim, desde o começo das pesquisas, optou-se, por razões teóricas, por não se incluir na pesquisa Belo Horizonte e toda sua região metropolitana. Já se sabia naquela época que, mesmo englobando algumas cidades de porte médio, a atmosfera da RMBH (como de qualquer região metropolitana) modifica o ambiente em que as cidades médias desenvolvem em plenitude as funções e as relações que, teoricamente, se esperam de tais cidades. Em suma, as características mais típicas das cidades médias são modificadas ou mascaradas naquelas cidades, por estarem inseridas em um organismo urbano de dimensão e complexidade bem maiores.
Um outro problema - de solução mais difícil - dizia respeito à escolha do limiar demográfico inferior, a partir do qual seria formado o grupo de cidades a ser pesquisado. A este respeito, assim se pronunciavam AMORIM FILHO; TAITSON BUENO; ABREU, em 1982:

A dificuldade maior apareceu quanto ao limiar inferior. Embora (...) o limite de 20.000 habitantes pareça ser o mais adequado para separar as médias das pequenas cidades, parece também evidente que as funções características das cidades médias possam ser exercidas por cidades com número inferior de habitantes, considerando-se a posição geográfica e as condições sócioeconômicas da região em que se situam as referidas cidades. Com base, então, nesse raciocínio e procurando trabalhar com a menor margem de erro possível, optou-se por incluir no universo de análise todas as cidades que tivessem cerca de 10.000 habitantes e mais na sede municipal em 1970 , com exclusão daquelas que fizessem parte da RMBH. Com isso, em um total de 722 cidades em todo o Estado, selecionaram-se 102 cidades. (AMORIM FILHO; TAITSON BUENO; ABREU, 1982, p. 35).

A maioria absoluta desses 102 municípios já havia sido objeto de trabalhos de campo realizados por Amorim Filho desde 1969. As cidades não pertencentes a essa maioria foram visitadas entre 1979 e $1981 .^{1}$

Quanto ao tratamento computacional dos dados, sob a responsabilidade de Abreu, a opção recaiu sobre uma técnica até então muito pouco utilizada no Brasil: uma Análise de Componentes Principais - ACP. Para essa classificação estatística das 102 cidades, 25 variáveis foram selecionadas, referindo-se aos seguintes parâmetros:

- crescimento da população urbana;

- migrações;

- distribuição setorial da população ativa;

- $\quad$ arrecadação municipal;

- $\quad$ equipamentos e relações dos setores comercial e de serviços;

- $\quad$ equipamentos e relações do setor industrial;

- infra-estrutura de comunicação em geral;

- posição da cidade considerada na rede urbana regional.

$1\left(^{*}\right)$ É importante recordar aqui que, de 1979 a 1982, Amorim Filho foi diretor da Divisão de Geografia do Instituto de Geociências Aplicadas do Estado de Minas Gerais (IGA-MG) e este fato facilitou consideravelmente as visitas às cidades mineiras. 
A ACP foi muito bem-sucedida, pois seus resultados apresentaram uma fortíssima compatibilização com os dados e impressões obtidos empiricamente e com as hipóteses teóricas.

Além de um conhecimento bem mais detalhado de cada uma das cidades de Minas Gerais, classificadas como médias, esta primeira classificação trouxe uma contribuição fundamental. É que, antes desta pesquisa, as reflexões teóricas e alguns estudos monográficos levavam a crer que o grupo das cidades médias fosse um grupo compacto, formado por cidades muito semelhantes entre si. Os estudos (especialmente os trabalhos de campo), que deram suporte e substância à publicação do texto de 1982, mostraram, de maneira clara, que não é bem assim. Na verdade, com esses estudos foi possível chegar à identificação de pelo menos quatro níveis hierárquicos no interior do grupo das cidades médias.

- Grandes Centros Regionais - Trata-se do limiar superior, que serve para fazer a transição entra as cidades médias de nível superior e as grandes cidades. Por isso, quando uma cidade é classificada na categoria de grande centro regional, haverá necessariamente certa imprecisão, encontrando-se pesquisadores e analistas que poderão incluí-la seja como cidade média, seja como cidade grande.

Esses grandes centros regionais possuem um forte contingente populacional: no caso de Minas Gerais, uma população urbana em torno de 400.000 habitantes. Possuem, igualmente, uma economia saudável, equilibrada em seus setores secundário e terciário, além de já apresentarem núcleos (mesmo que embrionários) de desenvolvimento de inovações tecnológicas. Polarizam vastos espaços regionais e mantêm relações econômicas, culturais e demográficas até mesmo com cidades e regiões situadas fora de Minas Gerais.

Cidades médias de nível superior: as cidades aqui incluídas são sempre visualizadas, em qualquer hierarquização, como cidades médias, quando se trata de classificações que cobrem todas as cidades do Estado. No interior de suas próprias regiões, são encaradas pela população regional como cidades grandes. São cidades que possuem um dinamismo demográfico sustentado e, no caso do estudo publicado em 1982, tinham populações que se situavam entre um pouco mais de 70.000 até cerca de 200.000 habitantes. São cidades que desenvolveram, paralelamente à indústria, dinâmicos setores de comércio e de serviços. Assim, essas cidades, além de fortalecerem sua posição e suas ligações no domínio regional, começam a estender essas ligações a pontos situados para além desses domínios. São, em síntese, cidades de estruturas já bem consolidadas e cujo crescimento futuro parece, sem dúvida, assegurado. (AMORIM FILHO; TAITSON BUENO; ABREU, 1982, p. 41).

- Cidades Médias Propriamente Ditas - Essas cidades são aquelas com características mais intermediárias, quando se trata do tamanho demográfico, da hierarquia e das funções econômicas. Em termos demográficos, há heterogeneidade neste nível hierárquico, mas as cidades aqui incluídas se encontram em sua quase totalidade com população entre 20.000 e 100.000 habitantes, ou seja, as cidades mais tipicamente médias, de acordo com os estudos pioneiros de pesquisadores franceses sobre o assunto (por exemplo, Joseph Lajugie, em 1974). Também em suas interações essas funções de intermediação se destacam:

Em suas relações externas, as cidades incluídas no grupo das médias (propriamente ditas) são caracterizadas por certos aspectos bem peculiares. De um lado, tendo em vista seu nível atual de desenvolvimento econômico, sua posição geográfica sempre nos eixos ou entroncamentos principais das vias de comunicação, essas cidades mantem relações importantes com centros maiores (...). De outro lado, essas cidades médias continuam a manter relações intensas, constantes e diretas com as cidades menores e com o espaço microrregional a elas ligado. É essa função de ligação entre o espaço rural e as pequenas cidades microrregionais, de uma parte, e os centros urbanos mais importantes, de outra, que constitui a própria essência dessa noção de cidade média, tão bem identificada nesse grupo de cidades... (AMORIM FILHO; TAITSON BUENO; ABREU, 1982, p. 43).

- Centros Urbanos Emergentes - Este nível hierárquico é formado por cidades que se encontram na faixa transicional entre as 
FILHO, O. B. A.; RIGOTTI, J. I. R.; CAMPOS, J. Os níveis hierárquicos das cidades médias de Minas Gerais

pequenas cidades e as cidades médias propriamente ditas. Em termos demográficos, normalmente os centros emergentes não chegam a 50.000 habitantes na sede municipal. A economia desses municípios em geral se encontra em fase de estruturação, podendo, portanto, apresentar desequilíbrios intersetoriais. Em muitos desses centros emergentes, observam-se importantes ligações com o mundo rural que os envolve:

... para esses espaços rurais, os centro urbanos emergentes representam a primeira válvula de abertura em relação ao mundo exterior. (AMORIM FILHO; TAITSON BUENO; ABREU, 1982, p. 44).

Tendo por base esses quatro níveis hierárquicos das cidades médias, excluída as cidades da Região Metropolitana de Belo Horizonte, o trabalho de 1982 chegou aos resultados apresentados no Quadro 1 e na Figura 1.
No quadro, alguns aspectos principais das cidades médias de Minas Gerais, no final dos anos 1970 e no início da década de 1980, merecem destaque:

- $\quad$ no nível mais alto da hierarquia, Juiz de Fora tem uma presença de liderança e polarização incontestáveis, localizada mais ou menos a meio caminho entre o Rio de Janeiro e Belo Horizonte; seu papel polarizador e sua supremacia regional não têm nenhum paralelo principalmente na Zona da Mata Mineira. Nas regiões limítrofes (Sul de Minas, Rio Doce e Campos das Vertentes, principalmente), sua influência ainda se mantém em alguns municípios, mesmo enfrentando a concorrência de outros pólos regionais importantes;

- no nível das cidades médias de nível superior (com exceção de São Lourenço e Caxambu, que por uma imprecisão do procedimento quantitativo foram inadequadamente classifi-

NÍVEL 1 (Grande Centro Regional): Juiz de Fora

NÍVEL 2 (Cidades Médias de Nível Superior): Uberlândia, Uberaba, Barbacena, Varginha, Poços de Caldas, Itajubá, Pouso Alegre, Governador Valadares, Sete Lagoas, Montes Claros, Divinópolis, São Lourenço e Caxambu.

NÍVEL 3 (Cidades Médias Propriamente Ditas): Teófilo Otoni, Patos de Minas, Ituiutaba, Caratinga, Araguari, Passos, São João del Rei, Formiga, Curvelo, Diamantina, Ubá, Araxá, Machado, Viçosa, Carangola, Itabira, Ponte Nova, Lavras, Alfenas, São Sebastião do Paraíso, Oliveira, Conselheiro Lafaiete, Três Corações, Itaúna, Leopoldina, Ouro Preto, Ouro Fino, Santa Rita do Sapucaí, Guaxupé, João Monlevade, Além Paraíba, Coronel Fabriciano, Pará de Minas, Cataguases, Ipatinga, Congonhas, Santos Dumont, Visconde do Rio Branco, Boa Esperança, Muriaé, São João Nepomuceno, Campo Belo, Nanuque.

NÍVEL 4 (Centros Emergentes): Patrocínio, Bom Despacho, Pirapora, Timóteo, Frutal, Tupaciguara, Manhuaçu, Sacramento, Manhumirim, Três Pontas, Arcos, Dores do Indaiá, São Gonçalo do Sapucaí, Itabirito, Nova Era, Bambuí, Janaúba, Monte Carmelo, Carmo do Paranaíba, Pium-í, Abaeté, Ibiá, Lagoa da Prata, Mantena, Corinto, Pedra Azul, São Gotardo, Santa Bárbara, Itapecerica, Resplendor, Raul Soares, Paracatu, Unaí, João Pinheiro, Itambacuri, Aimorés, Carlos Chagas, Januária, Bocaiúva, Conselheiro Pena, Araçuaí, Almenara, Salinas, Jequitinhonha, Mariana.

FONTE: Organizado por Amorim Filho, Taitson Bueno e Abreu (IGC-UFMG)

QUADRO 1 - HIERARQUIA DAS CIDADES MÉDIAS DE MINAS GERAIS - 1982 
FIGURA 1: HIERARQUIA DAS CIDADES MÉDIAS DE MINAS GERAIS - 1982

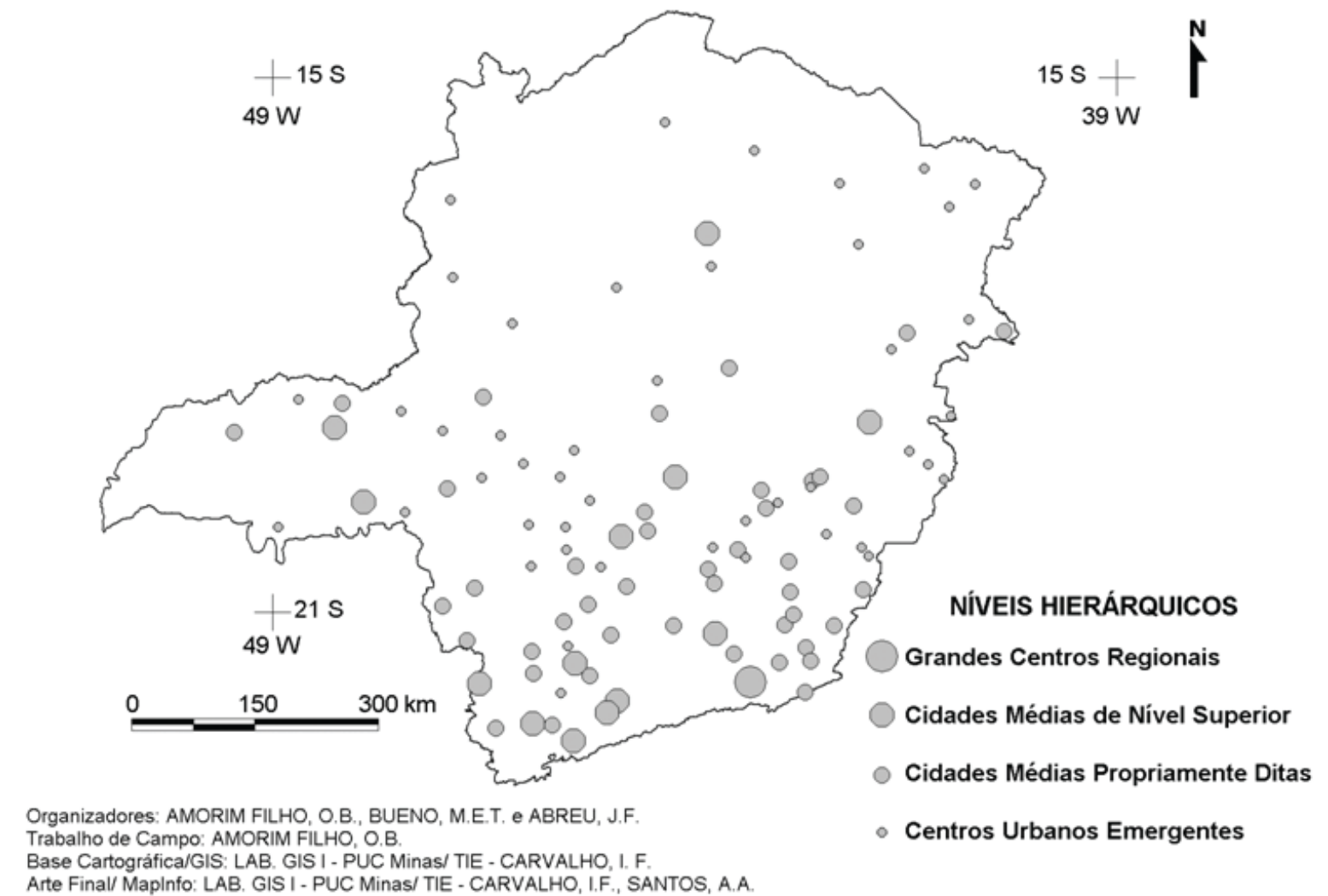

cadas neste nível), todas as cidades desenvolvem forte centralidade em suas regiões, com destaque para Uberlândia e Uberaba, no Triângulo Mineiro; Montes Claros, em grande parte do norte de Minas Gerais; e Governador Valadares, no médio Vale do Rio Doce, assim como em outras áreas do centro-leste mineiro e do centro-oeste capixaba;

- $\quad$ no nível das cidades médias propriamente ditas, foram incluídas 43 cidades, que se encontram majoritariamente na metade sul de Minas Gerais, especialmente em três mesorregiões: Zona da Mata, Sul de Minas e Zona Metalúrgica (não se considerando nesta última a RMBH); em termos demográficos, as cidades deste grupo têm apresentado um crescimento demográfico regular e sustentado, mas uma parte delas, em função de um ciclo importante de industrialização, tem acelerado seu crescimento (Ipatinga, Coronel Fabriciano, Divinópolis, João Monlevade, Conselheiro Lafaiete, entre outras); na metade norte de Minas Gerais, poucas são as cidades médias deste nível hierárquico presentes: a constatação desta carência reforça ainda mais a importância de cidades como Teófilo Otoni e Nanuque, além de uma série de centros emergentes, espalhados pela parte setentrional do estado;

- no nível dos centros urbanos emergentes, encontram-se 45 cidades com uma distribuição mais significativa justamente nas regiões em que as cidades dos níveis hierárquicos mais altos têm menor presença: norte e noroeste de Minas, Vale do Jequitinhonha, Médio e Alto Vales do São Francisco; este último aspecto permite levantar a hipótese de que, nessas 
regiões menos desenvolvidas socioeconomicamente, o papel e as funções de cidades médias hierarquicamente superiores podem (mesmo que precariamente) estar sendo exercidos por organismos urbanos menores e subequipados.

\section{A CLASSIFICAÇÃO DE 1999}

A maior parte da década de 1980 coincide com uma relativa queda de interesse pelas cidades médias, uma vez que essas cidades tinham estado, nos anos 1970 , muito ligadas às políticas de planejamento urbano e regional que se inspiraram na teoria dos pólos de crescimento.

Em função da diminuição de recursos para o planejamento urbano e regional, além de uma mudança de foco das políticas públicas, que preferem privilegiar problemas intra-urbanos (em especial aqueles ligados à pobreza nas grandes cidades e metrópoles), as cidades médias passam por uma fase de prestígio menor.

Porém, desde o alvorecer da década de 1990, as cidades médias voltam a figurar entre as prioridades não somente de acadêmicos e planejadores como, também, da mídia e da nova economia globalizada. Esse interesse, no decorrer dos anos 1990, se baseou no fato de que as cidades médias têm sido consideradas (com maior ou menor razão) como lugares privilegiados em termos de qualidade de vida, de preservação do meio ambiente e do patrimônio urbanístico, e como pólos de atração dos crescentes fluxos turísticos. Além disso, nos campos científico e tecnológico, as cidades médias têm sido muito vinculadas (principalmente na França) ao conceito de tecnópole, um dos mais importantes fenômenos da economia globalizada.

A esse respeito, pensou-se originalmente que as grandes cidades, capitais e metrópoles seriam os locais ideais para a criação dos pólos tecnológicos. De fato, as grandes aglomerações, principalmente nas regiões mais desenvolvidas do globo, apresentam-se como canditadas naturais a sediar esses complexos tecnológicos, cuja prioridade maior é a criação, reciclagem e difusão de inovações.

Porém, mesmo nos países pioneiros nesse campo, logo se viu que as grandes aglomerações, já saturadas, marcadas por deseconomias, não poderiam ter o monopólio desses espaços de inovações tecnológicas.

À medida que foram se desenvolvendo os projetos tecnopolitanos pelo mundo, novas exigências apareceram ligadas, de um lado, à necessidade desses espaços de inovações estarem ligados, com facilidade, a outros espaços congêneres, formando redes ou eixos complexos e, de outro lado, à necessidade, manifestada pelos homens envolvidos nessas experiências, de quadros de vida mais agradáveis, propiciando níveis altos de qualidade de vida.

Assim, na opinião de alguns dos mais eminentes estudiosos deste tema, os parques tecnológicos têm melhores condições de desenvolvimento bem-sucedido quando se localizam nas cidades médias. Dois dos mais conhecidos pesquisadores franceses, envolvidos com a questão dos tecnópolos, afirmaram que, na França, a tendência era a da "criação de pelo menos uma tecnópole por cidade média" (BURNIER; LACROIX, 1996, p. 46 e 47).

Tendo em vista essas considerações, a FAPEMIG financiou um projeto para que, sob a coordenação de Amorim Filho e a participação de Abreu, já no âmbito do Programa de Pós-Graduação em Geografia - Tratamento da Informação Espacial da PUC Minas, fosse realizada uma atualização dos conhecimentos sobre a rede e a hierarquia das cidades médias mineiras e, a partir daí, com a realização de trabalhos de campo, fossem identificadas aquelas que maior potencial apresentasse para se tornarem tecnópoles.

A pesquisa teve a duração de dois anos (1997 e 1998) e os resultados finais foram publicados em 1999.

No que diz respeito à metodologia, optou-se, desde o início, por usar como critérios quase todos aqueles que haviam sido utilizados na classificação de 1982, inclusive com a manutenção dos quatro níveis hierárquicos a que se tinha chegado naquele primeiro estudo. Porém, duas modificações importantes seriam feitas: a primeira teve a ver com a inclusão, entre as variáveis escolhidas para a classificação, de algumas que permitissem avaliar a importância das iniciativas de algumas cidades médias no campo das tecnologias de ponta; a segunda foi a de se incluir entre as variáveis, algumas mais ligadas ao tema da qualidade de vida urbana, inclusive o IDH.

Das cidades selecionadas para a pesquisa, foram eliminadas, a priori, aquelas da Região Metropolitana de Belo Horizonte (que, além das razões já utilizadas para sua eliminação no estudo de 1982, apresentam, como se sabe de antemão, a maior parte das condições para sediar um ou mais parques tecnológicos) e as pequenas cidades, grande maioria das sedes municipais em Minas, e que não têm, pelo menos por enquanto, como preencher os requisitos necessários à implantação de parques tecnológicos. 
As variáveis escolhidas foram agrupadas em oito indicadores principais, dotados, do ponto de vista teórico, de capacidade de identificar não somente uma hierarquia das cidades médias mineiras, como também de selecionar, entre elas, as que mais condições apresentavam de criar e desenvolver um parque tecnológico. Esses indicadores foram os seguintes:

1) população urbana;

2) índice de desenvolvimento humano (IDH);

3) renda familiar per capita média;

4) número de indústrias de ponta;

5) total de eixos rodoviários que convergem para cada cidade;

6) presença de aeroportos;

7) presença e número de cursos superiores.

Os resultados alcançados aparecem no Quadro 2 e na Figura 2, a seguir.

A elaboração dessa classificação é significativa, pois, mesmo levando-se em conta que tenha havido alterações em algumas das variáveis utilizadas, ela permite a comparação com o quadro hierárquico produzido em estudo semelhante, dos mesmos autores, publicado em 1982.
No nível hierárquico mais alto (grandes centros regionais), nota-se que Juiz de Fora continua a manter sua posição de destaque no cenário urbano de Minas Gerais, mas foi alcançada, e mesmo em alguns quesitos, superada pela cidade triangulina de Uberlândia, que, em 1982, estava em nível hierárquico inferior.

Entre as cidades médias de nível superior, Barbacena, Divinópolis, Governador Valadares, Itajubá, Montes Claros, Poços de Caldas, Pouso Alegre, Uberaba e Varginha mantiveram, em 1999, sua posição hierárquica de 1982.

Ipatinga, Coronel Fabriciano (ambas no nível 3, 1982) e Timóteo (no nível 4) passaram a formar, com outros municípios, uma nova aglomeração urbana (Região Metropolitana do Vale do Aço). Se essas cidades forem consideradas separadamente, cada uma aparecerá em um nível hierárquico diferente, com a ordem decrescente de Ipatinga, para Coronel Fabriciano e Timotéo. Se forem consideradas enquanto formadoras de uma nova unidade urbana (a RMVA), na qual também se incluem outros municípios, aí, então, sua classificação entre as cidades médias perde muito do sentido, uma vez que as regiões metropolitanas possuem dinâmicas próprias e só devem, por princípio de coerência lógica, ser comparadas entre elas mesmas. Outras cidades que se encontravam no nível 3 (cidades médias propriamente ditas) em 1982 e que, em 1999, subiram para o nível 2, são: Alfenas, Araguari, Ituiutaba, Lavras, Passos e Patos de Minas.

NÍVEL 1 (Grandes Centros Regionais): Juiz de Fora, Uberlândia.

NÍVEL 2 (Cidades Médias de Nível Superior): Alfenas, Araguari, Barbacena, Divinópolis, Governador Valadares, Ipatinga (aglomeração), Itajubá, Ituiutaba, Lavras, Montes Claros, Passos, Patos de Minas, Poços de Caldas, Pouso Alegre, Sete Lagoas, Uberaba, Varginha.

NÍVEL 3 (Cidades Médias Propriamente Ditas): Araxá, Caratinga, Cataguases, Conselheiro Lafaiete, Curvelo, Formiga, Frutal, Guaxupé, Itabira, Itaúna, João Monlevade, Leopoldina, Muriaé, Ouro Preto, Paracatu, Pará de Minas, Patrocínio, Ponte Nova, Santa Rita do Sapucaí, São João del Rei, São Lourenço, São Sebastião do Paraíso, Três Corações, Teófilo Otoni, Ubá, Viçosa.

NÍVEL 4 (Centros Emergentes): Abaeté, Aimorés, Além Paraíba, Almenara, Andradas, Araçuaí, Arcos, Bambuí, Barão de Cocais, Boa Esperança, Bocaiúva, Bom Despacho, Campo Belo, Carangola, Carlos Chagas, Carmo do Paranaíba, Caxambu, Congonhas, Conselheiro Pena, Corinto, Diamantina, Dores do Indaiá, Ibiá, Itabirito, Itambacuri, Itapecerica, Janaúba, Iturama, Januária, Jequitinhonha, João Pinheiro, Lagoa da Prata, Machado, Manhuaçu, Manhumirim, Mantena, Mariana, Monte Carmelo, Nanuque, Nova Era, Nova Serrana, Oliveira, Ouro Branco, Ouro Fino, Pedra Azul, Pirapora, Pium-í, Raul Soares, Resplendor, Sacramento, Salinas, Santa Bárbara, Santos Dumont, São Gonçalo do Sapucaí, São Gotardo, Três Pontas, Tupaciguara, Unaí, Visconde do Rio Branco.

FONTE: Organizado por Amorim Filho e Abreu (PUC Minas)

QUADRO 2 - HIERARQUIA DAS CIDADES MÉDIAS DE MINAS GERAIS - 1999 


\section{FIGURA 2: HIERARQUIA DAS CIDADES MÉDIAS DE MINAS GERAIS - 1999}

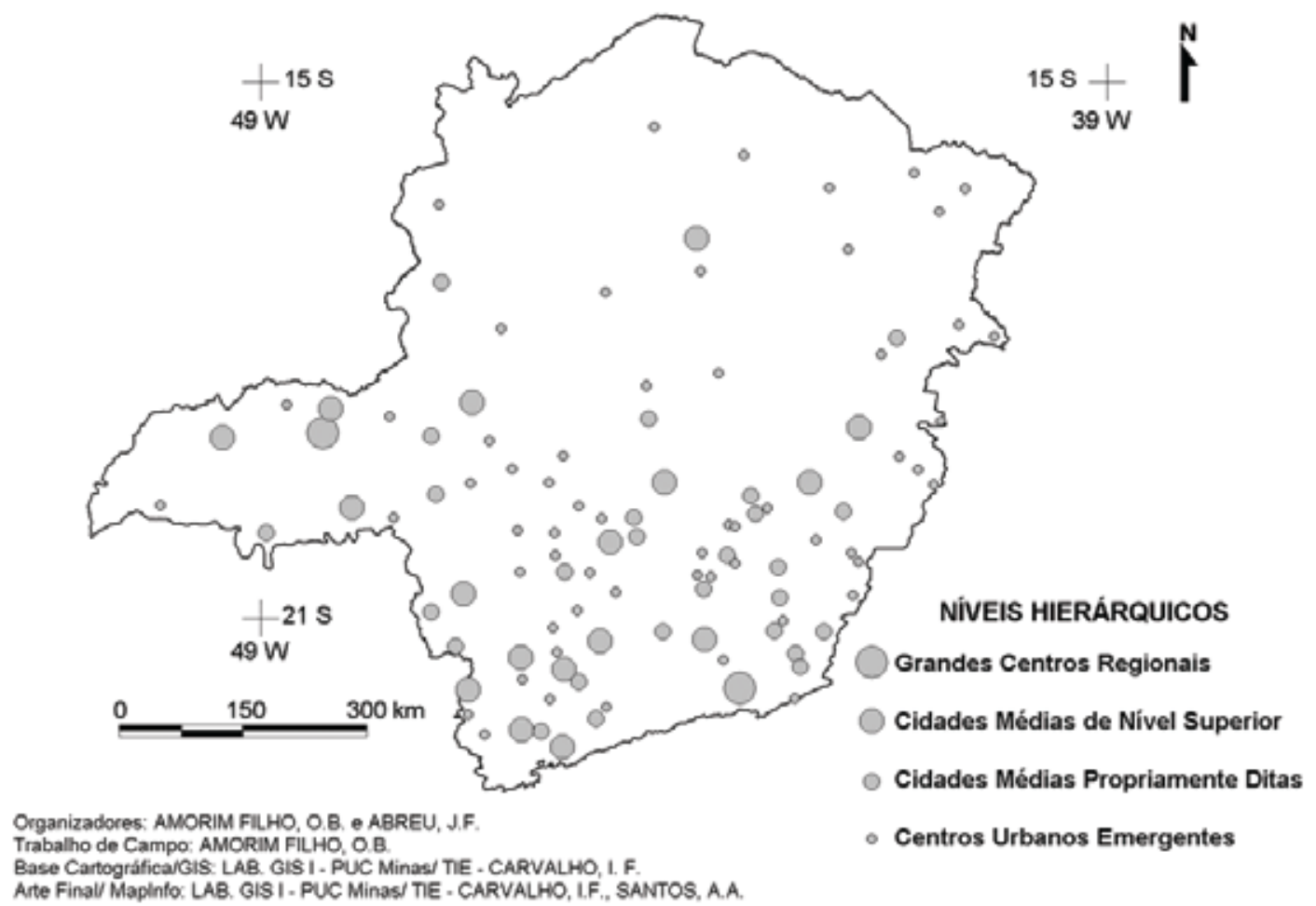

Por outro lado, São Loureço e Caxambu, cuja classificação no nível 2, em 1982, tinha sido, evidentemente, superestimada (por imprecisões técnicas), declinaram para níveis hierárquicos mais condizentes com suas reais posições na hierarquia das cidades médias mineiras, ou seja, São Lourenço, no nível 3, e Caxambu, no nível 4.

Nos níveis 3 e 4 , enquanto várias cidades conseguiram manter suas posições hierárquicas nos últimos 20 anos, muitas outras tiveram as respectivas posições alteradas. Um aspecto interessante é que, entre os dois estudos, houve um aumento geral no número de cidades do nível 4 (centros urbanos emergentes), enquanto diminuíram as cidades classificadas no nível 3 (cidades médias propriamente ditas).

Além das mudanças ligadas à própria dinâmica das cidades no sobe-e-desce entre os níveis das hierarquizações urbanas construídas com uma diferença de cerca de 20 anos, é possível que uma parte pelo menos dessas variações se deva à utilização de dados mais fidedignos e ao aperfeiçoamento das técnicas de tratamento desses dados e, ainda, a controles de campo cada vez mais eficientes.

\section{A HIERARQUIZAÇÃO EXPLORATÓRIA DE 2006}

Em 2003, o Colegiado do Programa de PósGraduação em Geografia - Tratamento da Informação Espacial da PUC Minas, com a finalidade de contrabalançar a tendência para uma pulverização temática exagerada nas pesquisas de seus docentes e discentes, criou cinco projetos permanentes de reflexão e pesquisa, coordenados por professores seniores, de larga experiência e forte produção científica, cobrindo os temas apresentados no Quadro 3.

A partir de então, portanto, um dos objetivos do coordenador deste projeto permanente (ou seja, que guarda sua continuidade, independentemente da existência, ou não, de financiamento externo para suas pesquisas) é o de manter sempre atualizadas as informações sobre as cidades médias de Minas Gerais. 
FILHO, O. B. A.; RIGOTTI, J. I. R.; CAMPOS, J. Os níveis hierárquicos das cidades médias de Minas Gerais

PROJETOS PERMANENTES (TEMAS)

PROFESSOR COORDENADOR

- Análise espacial e geoprocessamento João Francisco de Abreu

- Métodos matemáticos para a Geografia Leônidas Conceição Barroso

- Geomorfologia cárstica Heinz Charles Kohler

- Mudanças globais João Alberto Pratini de Moraes

- Cidades médias Oswaldo Bueno Amorim Filho

\section{QUADRO 3 - PROJETOS PERMANENTES DE PESQUISA DO PROGRAMA DE PÓS-GRADUAÇÃO EM GEOGRAFIA - TRATAMENTO DA INFORMAÇÃO ESPACIAL / PUC MINAS}

Essa é a motivação mais remota e profunda para o desenvolvimento do projeto sobre as cidades médias recentemente concluídas.

A outra motivação é o forte aumento do interesse acadêmico, dos planejadores urbanos-regionais e da mídia em relação às cidades médias, desde o início dos anos 1990.

Por outro lado, esse projeto visava, igualmente, produzir trabalhos para três encontros internacionais, que tiveram lugar no segundo semestre do ano de 2006, em Minas Gerais:

- $\quad$ na PUC Minas de Belo Horizonte (em outubro): o VI Seminário Latino-americano de Qualidade de Vida Urbana e o V Seminário Internacional de Estudos Urbanos;

- na Universidade Federal de Uberlândia (em novembro): o II Seminário Internacional sobre Cidades Médias.

A pesquisa teve início em 2005, com sua fase de campo, que propiciou a visita a 60 cidades que fazem parte da lista daquelas que, nas pesquisas anteriores, sempre foram classificadas como cidades médias. A segunda etapa da pesquisa consistiu num trabalho de gabinete, com o uso intensivo do geoprocessamento. São os resultados dessa pesquisa que discutiremos a partir deste momento.

Mais uma vez, Belo Horizonte e as demais cidades da $\mathrm{RMBH}$ foram descartadas pelos motivos teóricos já discutidos no presente texto.
O limiar demográfico inferior das cidades selecionadas para a pesquisa mudou de 10.000 habitantes, usado na primeira hierarquização (1982), para 14.000 habitantes. Essa mudança se deve a uma constatação de campo, de acordo como a qual, algumas cidades, a partir desse limiar demográfico, já começam, em certas regiões, a desenvolver, pelo menos parcialmente, equipamentos e funções próprios de cidades médias. Portanto, as cidades-sedes municipais, com populações inferiores a 14.000 habitantes, consideradas estatística e aprioristicamente como cidades pequenas, foram também descartadas.

O total de cidades selecionadas foi, então, de 131, que corresponderia, em princípio, ao número atual de cidades que podem ser consideradas médias em Minas Gerais, em seus quatro níveis hierárquicos.

Foram, em seguida, coletados dados sobre essas cidades e municípios, tendo em vista 39 variáveis, que cobrem os seguintes indicadores principais:

- demografia;

- atividades econômicas (agropecuárias e extrativas, industriais, comerciais e de serviços);

- comunicações e transportes.

Esses dados relativos a cada cidade foram correlacionados por meio da Análise de Componentes Principais, técnica confiável estatisticamente, já utilizada nas classificações anteriores. Os resultados obtidos foram testados, mapeados, colocados em um quadro, e aparecem a seguir. 
NÍVEL 1 (Grandes Centros Regionais): Juiz de Fora, Uberlândia.

NÍVEL 2 (Cidades Médias de Nível Superior): Araguari, Araxá, Barbacena, Conselheiro Lafaiete, Divinópolis, Governador Valadares, Ipatinga, Itabira, Montes Claros, Muriaé, Passos, Patos de Minas, Poços de Caldas, Pouso Alegre, Sete Lagoas, Teófilo Otoni, Uberaba, Varginha.

NÍVEL 3 (Cidades Médias Propriamente Ditas): Alfenas, Caratinga, Cataguases, Coronel Fabriciano, Curvelo, Formiga, Itajubá, Itaúna, Ituiutaba, João Monlevade, Lavras, Manhuaçu, Mariana, Ouro Preto, Pará de Minas, Paracatu, Patrocínio, Ponte Nova, São João del Rei, São Sebastião do Paraíso, Timóteo, Três Corações, Ubá, Unaí, Viçosa.

NÍVEL 4 (Centros Emergentes): Abaeté, Além Paraíba, Almenara, Andradas, Araçuaí, Arcos, Bambuí, Barão de Cocais, Barroso, Belo Oriente, Boa Esperança, Bocaiúva, Bom Despacho, Brasília de Minas, Buritizeiro, Cambuí, Campo Belo, Campos Gerais, Capelinha, Carangola, Carmo do Paranaíba, Caxambu, Cláudio, Congonhas, Corinto, Coromandel, Diamantina, Elói Mendes, Espinosa, Frutal, Guanhães, Guaranésia, Guaxupé, Ibiá, Itabirito, Itamarandiba, Itaobim, Iturama, Janaúba, Januária, Jequitinhonha, João Pinheiro, Lagoa da Prata, Leopoldina, Luz, Machado, Manhumirim, Mantena, Monte Carmelo, Monte Santo de Minas, Nanuque, Nepomuceno, Nova Era, Nova Serrana, Oliveira, Ouro Branco, Ouro Fino, Paraguaçu, Paraopeba, Pedra Azul, Perdões, Pirapora, Pitangui, Pium-í, Pompeu, Porteirinha, Prata, Sacramento, Salinas, Santa Bárbara, Santa Rita do Sapucaí, Santana do Paraíso, Santo Antônio do Monte, Santos Dumont, São Francisco, São Gonçalo do Sapucaí, São Gotardo, São João Nepomuceno, São Lourenço, Taiobeiras, Três Marias, Três Pontas, Tupaciguara, Várzea da Palma, Vazante, Visconde do Rio Branco.

FONTE: Organizado por Amorim Filho, Rigotti e Campos (PUC Minas)

\section{QUADRO 4 - HIERARQUIA DAS CIDADES MÉDIAS DE MINAS GERAIS - 2006}

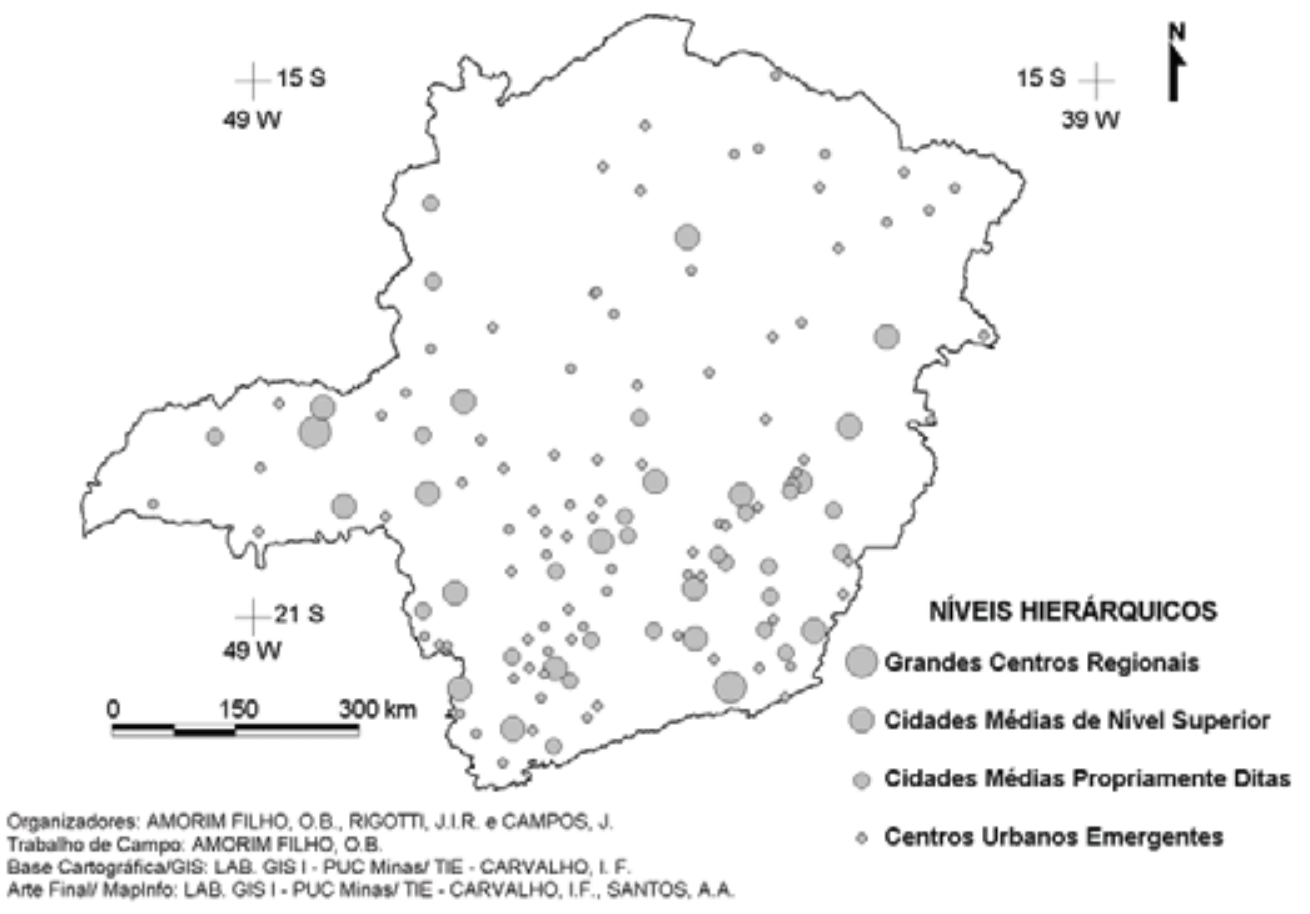

FIGURA 3 - HIERARQUIA DAS CIDADES MÉDIAS DE MINAS GERAIS - 2006 
Os resultados mostram-se bastante interessantes para os estudiosos das cidades médias mineiras. Alguns desses resultados são sintetizados a seguir.

- Juiz de Fora e Uberlândia, que na classificação de 1999 já tinham sido as únicas cidades a se colocarem no nível mais alto das cidades médias, mantiveram sua posição. Em relação a essas cidades, torna-se cada vez mais claro para o analista que elas deixam, tanto funcionalmente e demograficamente, quanto por suas relações externas e morfologia interna, o nível de cidades médias e entram no patamar das grandes cidades. As características e a intensidade de alguns problemas sociais que as duas cidades enfrentam confirmam que o limiar entre as médias e as grandes cidades está sendo, de fato, transposto pela capital da Zona da Mata e pela capital do Triângulo Mineiro.

- No patamar das cidades médias de nível superior, houve estabilidade quando se considera o número de cidades que se classificaram nesse nível: ele passou de 17, em 1999, para 18 em 2006. Mas, apesar de haver pouca mudança numérica, houve algumas modificações quanto às cidades incluídas nesse nível hierárquico:

- as cidades de Araxá, Conselheiro Lafaiete, Itabira, Muriaé e Teófilo Otoni, que em 1999 faziam parte do nível 3, subiram para o nível 2 em 2006;

- as cidades de Alfenas, Itajubá, Ituiutaba e Lavras, que, em 1999, faziam parte do nível 2, caíram para o nível 3, em 2006;

- as cidades de Araguari, Barbacena, Divinópolis, Governador Valadares, Ipatinga, Montes Claros, Passos, Patos de Minas, Poços de Caldas, Pouso Alegre, Sete Lagoas, Uberaba e Varginha mantiveram-se no mesmo patamar.

É importante considerar que as cidades de Montes Claros, Uberaba, Governador Valadares e Ipatinga são aquelas que, mesmo permanecendo no nível 2, mais se aproximam de uma ascensão para o nível 1 , dos grandes centros regionais.

No nível 3, aquele em que se classificam as cidades médias propriamente ditas, o número dessas cidades permaneceu quase inalterado entre as classificações de 1999 e 2006: diminuiu de 26 para 25.
Algumas cidades do nível 3 caíram para o nível 4: Frutal, Guaxupé, Leopoldina, Santa Rita do Sapucaí e São Loureço. Outras fizeram o caminho inverso: Coronel Fabriciano, Manhuaçu e Mariana. Esse sobe-e-desce de cidades entre os níveis hierárquicos não tem, necessariamente, a ver com uma diminuição ou um crescimento significativo de sua importância. Em muitos casos, o crescimento de certas cidades se mantém em vários setores e, mesmo assim, ela perde hierarquia. A razão pode estar no fato de que outra ou outras cidades cresceram em um ritmo ainda mais intenso. O mesmo raciocínio vale no caso oposto. Além disso, como já foi dito, embora os indicadores gerais sejam parecidos de uma classificação para a outra, as variáveis se modificam e isso interfere nos resultados, quando comparados. É preciso lembrar também que, embora as classificações sejam parecidas, algumas de suas motivações foram diferentes. Um exemplo disso está no caso de Santa Rita do Sapucaí, situada no sul de Minas, que obteve maior hierarquia em 1999, quando a finalidade era identificar, entre outras coisas, o potencial tecnopolitano. Em 2006, quando esse critério já não era prioritário, Santa Rita caiu para o nível dos centros urbanos emergentes. Com relação a estes últimos, que formam o nível de transição entre as cidades pequenas e as médias e, assim, abastecem, com o tempo, os níveis superiores dessas cidades, pode-se observar o seguinte:

- mesmo com a elevação do limiar demográfico inferior das cidades selecionadas para a pesquisa, de 10.000 habitantes urbanos na sede municipal, usado em 1982, para 14.000, em 2006, o número dos centros emergentes aumentou significativamente, passando de 45, em 1982, para 59 em 1999 e para 86 em 2006; isso quer dizer, provavelmente, que o número de cidades médias mineiras deverá crescer nos próximos anos;

- embora a distribuição geográfica dos centros emergentes venha se mantendo sem grandes alterações geográficas, uma mudança, porém, pode trazer esperança para aqueles que buscam um maior equilíbrio regional no estado: é que na metade norte de Minas Gerais, que dispõe de tão poucas e mal distribuídas cidades médias (Montes Claros, Teófilo Otoni, Paracatu e Unaí), observa-se um aumento importante de centros urbanos emergentes, e isso é um indício de que, talvez, mas próximas hierarquizações das cidades mineiras, o norte de Minas e os vales do Jequitinhonha e do Mucuri já passem a ter uma rede urbana mais equilibrada do que a da atualidade. 
FILHO, O. B. A.; RIGOTTI, J. I. R.; CAMPOS, J. Os níveis hierárquicos das cidades médias de Minas Gerais

\section{REFERÊNCIAS}

AMORIM FILHO, O. B. Contribution à l'étude des villes moyennes au Minas Gerais - Formiga et le Sud-Ouest du Minas Gerais. (Thèse de Doctorat). Bordeaux, Université de Bordeaux III, 1973. 361 p.

. Um esquema metodológico para o estudo das cidades médias. In: ENCONTRO NACIONAL DE GEÓGRAFOS 2. 1976, Belo Horizonte. Anais... Belo Horizonte: IGC/UFMG, 1976. p. 6-15. 600 p.

AMORIM FILHO, O. B.; BUENO, M. E. T.; ABREU, J. F. Cidades de porte médio e o programa de ações sócioeducativo-culturais para as populações carentes do meio urbano em Minas Gerais. Boletim de Geografia Teorética, Rio Claro, v. 12 n. 23-24, 33-46, 1982.

AMORIM FILHO, O. B.; ABREU, J.F. Ciudades Intermedias y Tecnópoles potenciales en Minas Gerais - Brasil. Tiempo y Espacio, Chillán v. 8, n. 9-10, p. 23-32, Universidad del BíoBío, 2000 (publicada em 2001).
AMORIM FILHO, O. B.; RIGOTTI, J. I. R. Os Limiares Demográficos na Caracterização das Cidades Médias. Encontro da Associação Brasileira de Estudos Populacionais, 13., 2002, Ouro Preto, Anais... Ouro Preto, 2002. 22 p. (meio digital).

BURNIER, M.; LACROIX, G. Les technopoles. Paris: PUF, 1996. $127 \mathrm{p}$.

DINIZ, A. M. A.; RIBEIRO, J. P. Violência urbana nas cidades médias mineiras: determinantes e implicações. Geosul, Florianópolis, v. 40, 2005.

LAJUGIE, J. Les villes moyennes. Paris; Éditions Cujas, 1974. 